\title{
Radiological Significance of Symmetric Central Tegmental Tract Hyperintensity in Pediatric Patients
}

\author{
Ugur Kesimal (iD ${ }^{1,}{ }^{*}$, Kamil Karaali (iD ${ }^{1}$ and Utku Senol (iD ${ }^{1}$ \\ ${ }^{1}$ Department of Radiology, Akdeniz University Faculty of Medicine Hospital, Akdeniz University, Antalya, Turkey \\ "Corresponding author: Department of Radiology, Akdeniz University Faculty of Medicine Hospital, Akdeniz University, Antalya, Turkey. Email: ugur_kesimal@hotmail.com \\ Received 2020 August 01; Revised 2021 January 25; Accepted 2021 January 30.
}

\begin{abstract}
Background: The central tegmental tract (CTT) is an extrapyramidal tract between the red nucleus and the inferior olivary nucleus which is part of the Guillain-Mollaret triangle (dentato-rubro-olivary system). Symmetric central tegmental tract hyperintensity (CTTH) is a pediatric brain magnetic resonance imaging (MRI) finding with an unclear clinical and radiological significance.

Objectives: The aim of this retrospective study is to determine the radiological significance of CTTH on magnetic resonance imaging (MRI) in children.

Patients and Methods: Pediatric patient's MRI from January 2015 to January 2017 were retrospectively reviewed in this case series study. Patient records with presence of CTTH in their MRI were evaluated.

Results: There were 39 out of 2981 brain MRIs with CTTH with a prevalence of 1.3\%. Some CTTH lesions disappeared on follow-up. In two patients, the disappearance of CTTH temporally corresponded to clinical improvement. Also we had patients with hemolytic uremic syndrome, autoimmune hemolytic anemia, Wilson's disease, combined immunodeficiency, Bartter syndrome, and autism. Conclusion: CTTH could be caused by a physiological maturation process or a physiological response of the cells in the central tegmental tract to a more widespread toxic/metabolic or ischemic insult in the brain. CTTH also appears to have a transient nature in some cases. Further research elucidating the pathophysiology of CTTH is needed.
\end{abstract}

Keywords: Central Tegmental Tract Hyperintensity, Children, Magnetic Resonance Imaging, Epilepsy, Metabolic Disease

\section{Background}

The central tegmental tract (CTT) is an extrapyramidal tract between the red nucleus and the inferior olivary nucleus which is part of the Guillain-Mollaret triangle (dentato-rubro-olivary system). It is located bilaterally and symmetrically in the posterior part of the brainstem (Figure 1). This tract also includes the ascending afferent fibers that connect reticular nuclei to the thalamus. Myelination of CTT starts at approximately 9 months in fetal life and completes around the first year of age. Symmetric central tegmental tract hyperintensity $(\mathrm{CTTH})$ is a pediatric brain magnetic resonance imaging (MRI) finding with an unclear clinical and radiological significance $(1,2)$. This phenomenon has been associated with various disorders including epilepsy, cerebral palsy, antiepileptic medications, hypoxic-ischemic encephalopathy, neoplasms, and neurodevelopmental disorders (1-13).

\section{Objectives}

Despite the wide range of clinical conditions reported, how often this finding is seen with disorders and whether

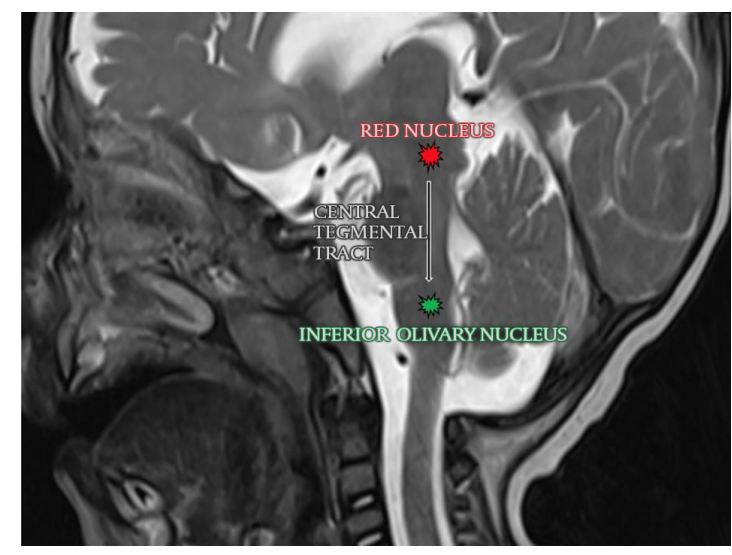

Figure 1. The central tegmental tract is located in tegmentum pontis between the red nucleus and the inferior olivary nucleus.

it could also be a benign, incidental finding is not yet known. Therefore, this retrospective study was planned to determine the radiological significance of CTTH retrospec- 
tively.

\section{Patients and Methods}

This retrospective case series study was approved by the Institutional Review Board (protocol number: 5.12.2018-852).

\subsection{Patient Population}

Pediatric patients ( 0 - 18 years) who underwent brain MRI for any indication at our institution between January 2015-January 2017 were included in the study. The reports of all imaging studies were evaluated for CTTH.

The images were independently reviewed by two experienced radiologists. Images in which the radiologists agreed on the presence of CTTH were included in the study. All available brain MRI studies of those patients were evaluated to determine the temporal course of CTTH. Patient records were reviewed from the electronic records system to gather relevant clinical data including the age and gender of the patient and their diagnoses, if any. The exclusion criteria were nondiagnostic imaging due to artifacts, operation before imaging, and inappropriate clinical data.

\subsection{MRI Technique}

MRI examinations were performed after obtaining informed consent from the parents. Sedation was given to patients by an anesthesiologist if required. MRI images were acquired with 3T (Magnetom Spectra) or 1.5T (Avanto or Aera) scanners (Siemens, Erlangen, Germany). The scanner used was determined on a case-by-case basis based on the clinical indication of the exam and the availability of the scanners.

The scanning protocol varied based on the clinical indication, with axial Turbo Spin Echo (TSE) T2, T1, Fluid attenuated inversion recovery (FLAIR); sagittal TSE T1 and axial diffusion weighted imaging (DWI) $(b=0, b=1000)$ being present in all cases. For the purposes of this study, T2weighted images (T2WI) and DWI were used.

CTTH was defined as bilateral symmetric hyperintensity in the tegmentum that could be seen on both T2WI and DWI images in more than two consecutive slices as described by Yoshida et al. (1).

\subsection{Statistical Analysis}

Statistical analysis was performed using statistical package for the social sciences (SPSS) version 15.0.0 (IBM Corp, Armonk, New York, USA). Frequencies were given in percentage.

\section{Results}

\subsection{Patient Population}

Initial search revealed 2985 patients with brain MRI. Four cases only had DWI imaging and were excluded. Of the remaining 2981 patients, 42 (1.4\%) had CTTH. Evaluation of these by both radiologists determined by consensus that $39(1.3 \%)$ of them fulfilled the criteria described by Yoshida et al. The demographical, clinical and radiological features of these patients are presented in Table 1 . The oldest patient was 215 months old (17 years) and the youngest was 8 days old (mean age: $37.43 \pm 49.98$ months, median age: 21 months).

\subsection{Imaging Findings}

These 39 patients had in total, 82 MRI studies. Fortyseven of these were scanned with the 3T scanner and the remaining 35 were scanned with one of the $1.5 \mathrm{~T}$ scanners (19 Avanto, 16 Aera, Siemens, Erlangen, Germany).

Twenty-three patients had follow-up MRIs (mean follow-up: $9.96 \pm 12.83$ months, median follow-up: 4.13 months). Three patients had no CTTH in their first MRI (Figure 2) but developed it in the follow-up MRIs at 8, 18, and 23 months of follow-up. Only one of those patients were further followed-up for 18 more months, during which CTTH was still present. In contrast, five patients had resolution of CTTH during follow-up at 19 days, 2.5, 7, 20, and 24 months of follow-up. Only one of those patients were further followed-up for 24 months and CTTH did not reappear in that interval. Interestingly, in two patients, CTTH was absent on initial scans, appeared during follow-up and then resolved. One of these two patients had neuroblastoma and Wernicke encephalopathy (Figure 3) and the other had acute lymphoblastic leukemia (ALL). Both stayed in the pediatric intensive care unit (ICU) for a long time, improved with treatment and the disappearance of CTTH temporally corresponded to clinical improvement.

Four of the five patients whose CTTH resolved were scanned with $1.5 \mathrm{~T}$ scanners at the time of resolution. In one other patient, CTTH was observed to have lower signal intensity in the $1.5 \mathrm{~T}$ images compared to previous $3 \mathrm{~T}$ images of the same patient. This patient was followed-up for 33 months, with all further follow-ups being at a 1.5 T scanner and demonstrating similar findings.

CTTH was the only radiologic abnormality in 10 patients. The remaining 29 had other radiological findings ranging from hypogenesis of the corpus callosum to hemorrhage and findings suggestive of metabolic disorders such as white matter hyperintensities or atrophy.

\subsection{Clinical Findings}

Seizures were present in 18 patients, 11 were diagnosed with epilepsy and eight were on antiepileptic medications 

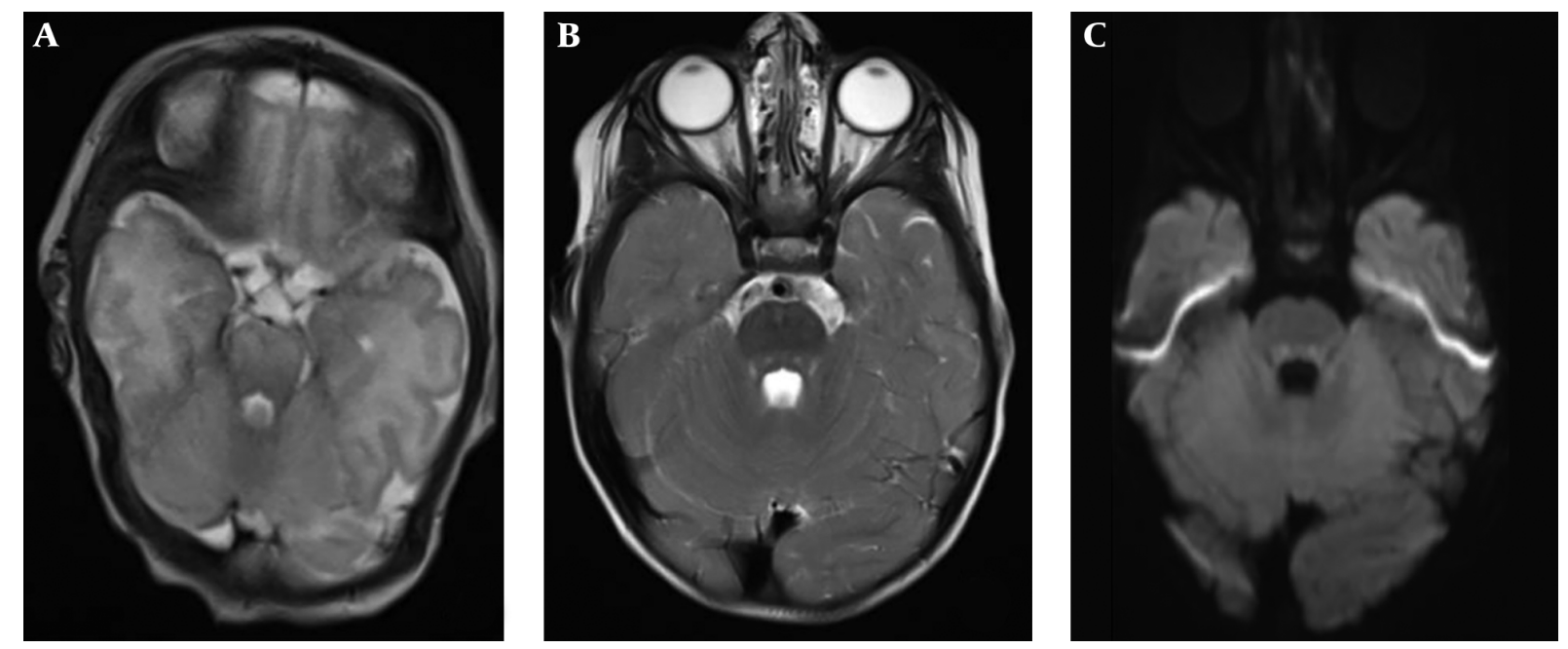

Figure 2. Brain MRI of a 4,2 month-old preterm boy with hypotonia and periventricular leukomalacia (patient No. 34). He had no central tegmented tract hyperintensity (CTTH) in his first MRI, and CTTH cannot be identified on the axial T2 weighted image (A). He developed CTTH in the follow-up MRI at 23 months. CTTH is evident on axial T2 weighted image (B) and diffusion weighted imaging (DWI) (C).
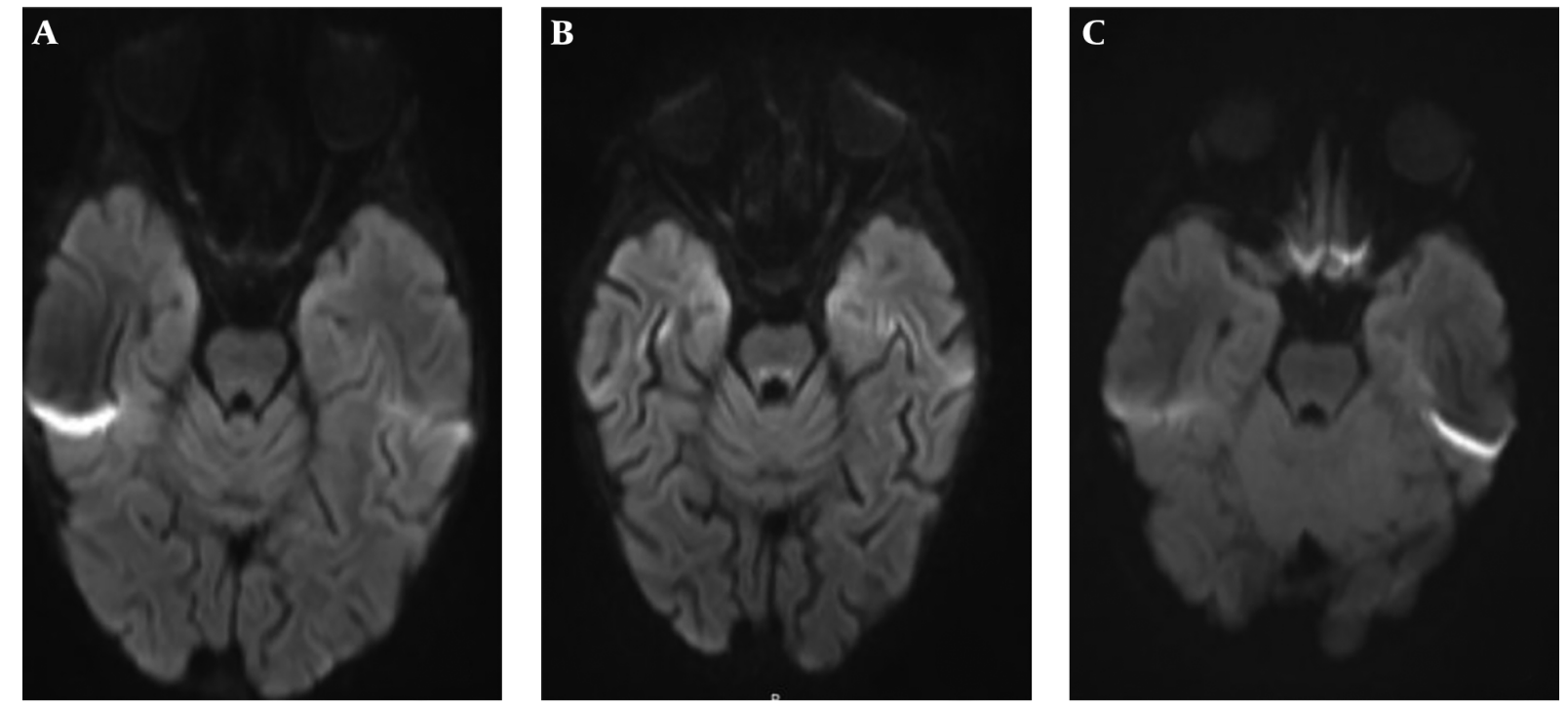

Figure 3. Brain MRI of a 2.5 year-old girl with acute lymphoid leukemia (patient No. 29). Central tegmented tract hyperintensity (CTTH) is not detected in the first diffusion weighted imaging (DWI) (A). CTTH appeared during follow-up DWI (B) and then resolved on 24 months follow-up DWI (C).

at the time of MRI. Two patients with epilepsy were diagnosed with West syndrome and were on vigabatrin. The other diagnoses were as follows: two patients with nonketotic hyperglycinemia, five patients with mitochondrial diseases (one of them was mitochondrial encephalomyopathy, lactic acidosis, Stroke-like episodes [MELAS]), two patients with genetic disorders (mosaic trisomy and congenital nonsyndromic sensorineural hearing loss), two patients with cerebral palsy, two patients with neuroblas- toma, three patients with leukemia (two acute myeloid, one acute lymphoblastic), one patient with hemolytic uremic syndrome (HUS) related to renal transplantation, one patient with autoimmune hemolytic anemia, two patients with autism, one patient with acute disseminated encephalomyelitis (ADEM), one patient with Bartter syndrome and one patient with combined immunodeficiency. Nine of the patients passed away during follow-up. 


\section{Discussion}

CTT is a bundle of efferent fibers located between the mediocentral tegmentum of the pons and dorsomedial part of the medulla oblongata (14). Under normal circumstances, CTT cannot be observed using conventional MRI sequences (2) but can be observed using diffuse tensor imaging (DTI) and tractography (15). Visualization of CTT in T2 weighted or DWI images is possible in certain disorders, where degeneration of the white matter tracts, edema and gliosis probably accounts for the increased signal (central tegmental tract hyperintensity) in these sequences (2).

The prevalence of this finding in pediatric brain MRIs has been reported to be $2.8 \%-5 \%(1,2)$. Our cohort had a smaller prevalence of $1.3 \%$. We believe this is related to our patient population, which includes larger-than-average numbers of normal imaging studies due to free healthcare and low threshold of clinicians at our institution for imaging.

Many clinical conditions have been associated with CTTH, such as cerebral palsy $(1,2)$, epilepsy, antiepileptic medications, metabolic disorders, post-chemotherapy syndrome, hypotony, Gorlin syndrome, encephalopathy, developmental delay and craniosynostosis (1-13). However, the clinical significance of this finding, especially whether the presence or absence of it has any prognostic or symptomatic relevance and whether the emergence or disappearance of the hyperintensity correlates to changes in clinical presentation is unclear.

Yoshida et al. (1), in their study of 395 brain MRIs, reported the most common associated clinical condition to be cerebral palsy (CP) and reported 30\% of their CTTH cases had CP. Derinkuyu et al. (13) similarly reported a high incidence of CTTH in their cerebral palsy patients compared to the control group (19\% vs. 3.5\%). In our cohort, we only had two patients (5.1\%) with CP, which is more similar to the results reported by Isik and Dincer (2), in which one out of 34 cases $(2.9 \%)$ of CTTH had CP. This discrepancy in the most common etiology is probably caused by different patient populations, single or multi-center nature of the studies and the relatively small number of patients included. The most common associated clinical conditions in our study were seizures and antiepileptic medications; both of which are well known associations of CTTH. Importantly, two of our patients with epilepsy were diagnosed with West syndrome and were on vigabatrin, which has been specifically reported to be associated with $\mathrm{CTTH}(2,3$, 7).

This study also reports some potential associations that have not been previously reported. We had patients with hemolytic uremic syndrome, autoimmune hemolytic anemia, Wilson's disease, combined immunodeficiency, Bartter syndrome and autism (two patients with autism, one patient each for other conditions). None of these dis- orders have been associated with CTTH. However, our data regarding these has limitations. The patient with autoimmune hemolytic anemia (AIHA) also had widespread cutaneous candidiasis. While cutaneous candidiasis is a different entity than systemic candidiasis (16), widespread manifestations could be related to immunologic disorders (17). Therefore, in this patient it is still possible that CTTH could be related to unknown factors at that time, rather than AIHA. One of the patients with autism was also diagnosed with epilepsy, so it is more likely that CTTH in that patient was related to the seizures. However, the other patient had atypical autism and no other diagnoses as far as could be determined based on patients' medical records.

CTTH also appears to have a transient nature in some cases. We had three patients with newly appearing CTTH during their follow-up for disease and five patients in whom CTTH disappeared during follow-up. This seems to support the hypothesis that CTTH is related to a maturation-related physiologic process that could be modified by endogeneous or external factors as speculated by Aguilera-Albesa et al. (7). In favor of this idea is also the observation that CTTH is always bilateral, even if the underlying associated condition is not $(1,2)$. It is possible that at a specific timepoint of this maturation process, CTT is more susceptible to toxic, ischemic or metabolic injury or accumulation, which leads to the increased T2 and DWI signal. As the maturation is complete, the signal changes become less prominent and the finding is not observed anymore. This is supported by the fact that CTTH is reported almost always in young children between 4 months and 8 years of age $(2,7,13)$. However, older patients up to 15 years old have also been reported by Derinkuyu et al. (13) in cerebral palsy patients. We had patients ranging from 8 days old to 17 years old, with the majority being younger than 8 years. Two of the older patients had neuroblastoma and acute myeloid leukemia with graft-versus-host disease. It is possible that in these patients, the lesions actually represented real tumor deposits rather than the more conventional 'physiologic' CTTH, accounting for the finding at a later age. In fact, in the neuroblastoma patient, $\mathrm{CTTH}$ disappeared with treatment, which could further support our hypothesis. Another patient had Wilson's disease (16 years-old). This patient had similar lesions in the thalamus, lentiform nucleus and caudate nucleus bilaterally and we believe CTTH was related to either copper accumulation or toxic effects related to this accumulation. Since the accumulation did not decrease in time, the imaging finding probably also persisted. Finally, our oldest patient (17yearsold) had known epilepsy and congenital hearing loss. In this patient, we cannot speculate as to the reason of the persistence of CTTH for so long. It is clear that at this point, our knowledge regarding this entity is lacking and the etiology and mechanisms of CTTH require further studies.

Our study also had limitations. The most important 
was the retrospective nature of the study. This means that the diagnosis, examination findings and clinical course of the patients all had to be gathered from patient charts, which limited our access to information that might have been potentially relevant. Due to the same reason, the follow-up MRIs of the patients were not uniform or according to a certain, single protocol. This caused some exams to be on $3 \mathrm{~T}$ scanners and some on $1.5 \mathrm{~T}$, which could have caused us to miss some lesions on $1.5 \mathrm{~T}$ scanners that might have been seen on $3 \mathrm{~T}$. We also did not review all brain MRIs but used the reports to determine the patients with CTTH. While this might have caused us to miss some patients where the finding was not reported, we believe the number of such cases would be small since all the reports have either been written or approved by faculty members with more than 15 years of pediatric radiology experience and with knowledge and awareness of CTTH.

In conclusion, CTTH can be seen in association with many different disorders, most importantly epilepsy and antiepileptic use. It is observed mostly in children younger than 8 years old but can be seen as late as 17 years of age. In a significant number of patients, the finding appears or disappears during the course of disease with no clear association with clinical findings at the time. We believe it is caused by a physiological maturation process or a physiological response of the cells in CTT to a more widespread toxic/metabolic or ischemic insult in the brain. Further research elucidating the pathophysiology of CTTH and confirming our findings in prospective studies is needed.

\section{Footnotes}

Authors' Contributions: Study concept and design: UK, KK, and US. analysis and interpretation of data: UK, KK, and US. Drafting of the manuscript: UK, KK, and US. Critical revision of the manuscript for important intellectual content: UK, KK, and US. Statistical analysis: UK.

Conflict of Interests: All authors declare there is no conflict of interest.

Ethical Approval: This study was approved by the Institutional Review Board (protocol number: 5.12.2018-852).

Funding/Support: The authors received no financial support for the research, authorship, and/or publication of this article.

\section{References}

1. Yoshida S, Hayakawa K, Yamamoto A, Aida N, Okano S, Matsushita H, et al. Symmetrical central tegmental tract(CTT) hyperintense lesions on magnetic resonance imaging in children. Eur Radiol. 2009;19(2):4629. doi: 10.1007/s00330-008-1167-7. [PubMed: 18795297].
2. Isik U, Dincer A. Central tegmentum tract hyperintensities in pediatric neurological patients: Incidence or coincidence. Brain Dev. 2017;39(5):411-7. doi: 10.1016/j.braindev.2016.11.013. [PubMed: 28010956].

3. Yoshikawa H, Nakano K, Watanabe S. Central tegmental tract lesion in a girl with holoprosencephaly presenting with West syndrome. Eur J Paediatr Neurol. 2009;13(4):376-9. doi: 10.1016/j.ejpn.2008.06.009. [PubMed: 18692418].

4. Takanashi J, Kanazawa M, Kohno Y. Central tegmental tract involvement in an infant with 6-pyruvoyltetrahydropterin synthetase deficiency. AJNR Am J Neuroradiol. 2006;27(3):584-5. [PubMed:16551996].

5. Tada H, Takanashi J, Barkovich AJ, Yamamoto S, Kohno Y. Reversible white matter lesion in methionine adenosyltransferase I/III deficiency. AJNR Am J Neuroradiol. 2004;25(10):1843-5. [PubMed: 15569761].

6. Khong PL, Lam BC, Chung BH, Wong KY, Ooi GC. Diffusion-weighted MR imaging in neonatal nonketotic hyperglycinemia. AJNR Am J Neuroradiol. 2003;24(6):1181-3. [PubMed: 12812951].

7. Aguilera-Albesa S, Poretti A, Honnef D, Aktas M, Yoldi-Petri ME, Huisman TA, et al. T2 hyperintense signal of the central tegmental tracts in children: disease or normal maturational process? Neuroradiology. 2012;54(8):863-71. doi: 10.1007/s00234-012-1006-z. [PubMed: 22271318].

8. Mohammad SA, Abdelkhalek HS, Ahmed KA, Zaki OK. Glutaric aciduria type 1: neuroimaging features with clinical correlation. Pediatr Radiol. 2015;45(11):1696-705. doi: 10.1007/s00247-015-3395-8. [PubMed: 26111870].

9. Mkaouar-Rebai E, Kammoun F, Chamkha I, Kammoun N, Hsairi I, Triki C, et al. A de novo mutation in the adenosine triphosphatase (ATPase) 8 gene in a patient with mitochondrial disorder. J Child Neurol. 2010;25(6):770-5. doi: 10.1177/0883073809344351. [PubMed: 20207608].

10. Sakai Y, Kira R, Torisu H, Ihara K, Yoshiura T, Hara T. Persistent diffusion abnormalities in the brain stem of three children with mitochondrial diseases. AJNR Am J Neuroradiol. 2006;27(9):1924-6. [PubMed: 17032867].

11. Sugama S, Eto Y. Brainstem lesions in children with perinatal brain injury. Pediatr Neurol. 2003;28(3):212-5. doi: 10.1016/s08878994(02)00623-9. [PubMed: 12770675].

12. Wheless JW, Carmant L, Bebin M, Conry JA, Chiron C, Elterman RD, et al. Magnetic resonance imaging abnormalities associated with vigabatrin in patients with epilepsy. Epilepsia. 2009;50(2):195-205. doi: 10.1111/j.1528-1167.2008.01896.x. [PubMed: 19054414].

13. Derinkuyu BE, Ozmen E, Akmaz-Unlu H, Altinbas NK, Gurkas E, Boyunaga $O$. A magnetic resonance imaging finding in children with cerebral palsy: Symmetrical central tegmental tract hyperintensity. Brain Dev. 2017;39(3):211-7. doi: 10.1016/j.braindev.2016.10.004. [PubMed: 27843044].

14. Shioda M, Hayashi M, Takanashi J, Osawa M. Lesions in the central tegmental tract in autopsy cases of developmental brain disorders. Brain Dev. 2011;33(7):541-7. doi: 10.1016/j.braindev.2010.09.010. [PubMed: 20970935].

15. Kamali A, Kramer LA, Butler IJ, Hasan KM. Diffusion tensor tractography of the somatosensory system in the human brainstem: initial findings using high isotropic spatial resolution at 3.0 T. Eur Radiol. 2009;19(6):1480-8. doi: 10.1007/s00330-009-1305-x. [PubMed: 19189108].

16. Ruhnke M. Epidemiology of Candida albicans infections and role of non-Candida-albicans yeasts. Curr Drug Targets. 2006;7(4):495-504. doi: 10.2174/138945006776359421. [PubMed: 16611037].

17. Palese E, Nudo M, Zino G, Devirgiliis V, Carbotti M, Cinelli E, et al. Cutaneous candidiasis caused by Candida albicans in a young non-immunosuppressed patient: an unusual presentation. Int I Immunopathol Pharmacol. 2018;32:2058738418781370. doi: 10.1177/2058738418781368. [PubMed: 29882446]. [PubMed Central: PMC6398342] 
Table 1. Demographical, Clinical and Radiological Features of Patients

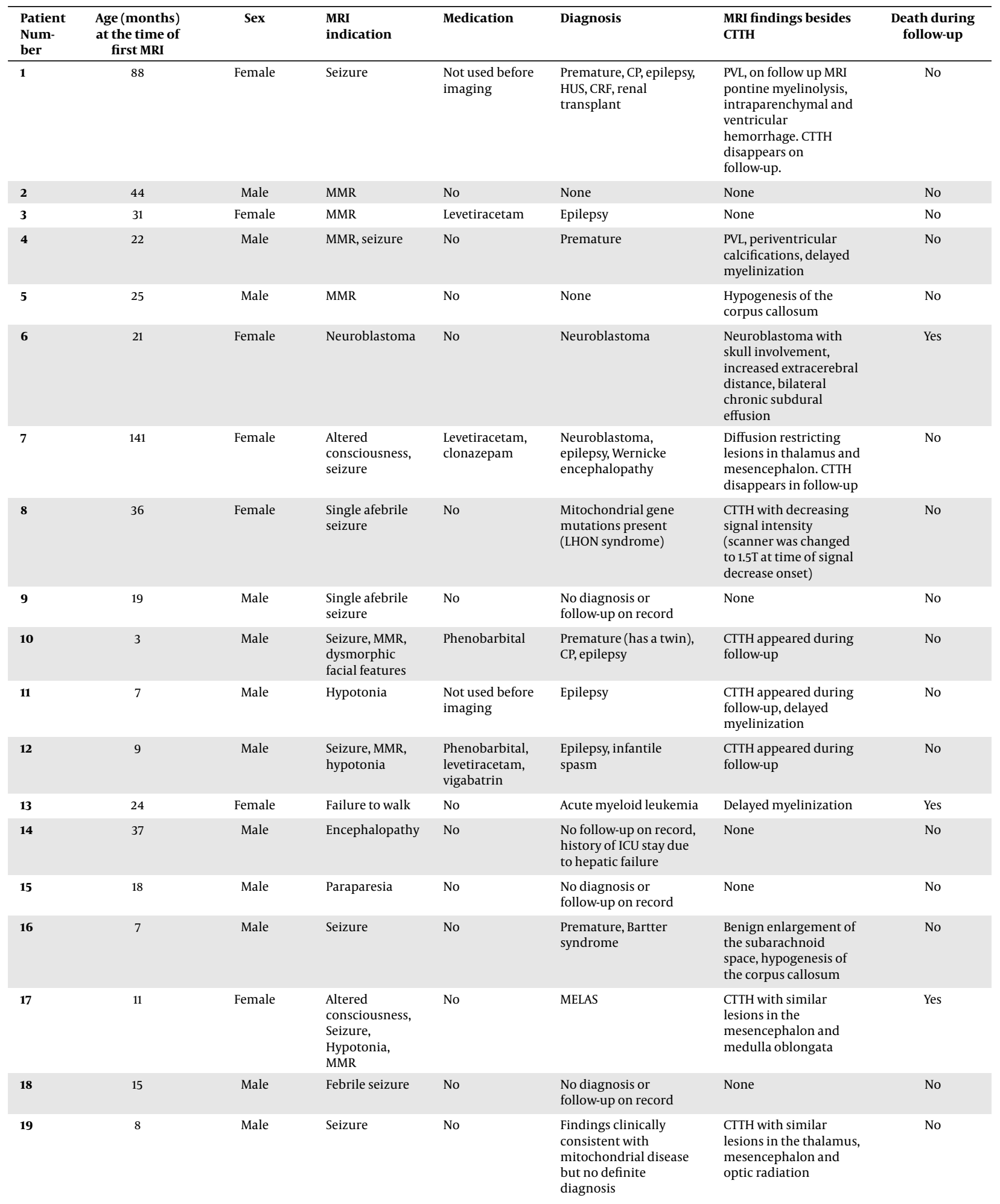


Kesimal U et al.

\begin{tabular}{|c|c|c|c|c|c|c|c|}
\hline 20 & 66 & Female & Seizure, MMR & $\begin{array}{l}\text { Not used before } \\
\text { imaging }\end{array}$ & $\begin{array}{l}\text { Findings clinically } \\
\text { consistent with } \\
\text { mitochondrial disease } \\
\text { but no definite } \\
\text { diagnosis, epilepsy }\end{array}$ & $\begin{array}{l}\text { CTTH with similar } \\
\text { lesions in the pons and } \\
\text { cerebellum }\end{array}$ & Yes \\
\hline 21 & 18 & Male & $\begin{array}{l}\text { MMR, } \\
\text { hypotonia }\end{array}$ & No & $\begin{array}{l}\text { Premature, findings } \\
\text { clinically consistent } \\
\text { with mitochondrial } \\
\text { disease but no definite } \\
\text { diagnosis }\end{array}$ & $\begin{array}{l}\text { Periventricular } \\
\text { increased signal }\end{array}$ & No \\
\hline 22 & 29 & Female & $\begin{array}{l}\text { MMR, } \\
\text { hypotonia }\end{array}$ & No & None & None & No \\
\hline 23 & 113 & Male & $\begin{array}{l}\text { Altered } \\
\text { consciousness, } \\
\text { fever }\end{array}$ & No & $\begin{array}{l}\text { Acute myeloid } \\
\text { leukemia, GVHD. }\end{array}$ & $\begin{array}{l}\text { Ventricular } \\
\text { hemorrhage on } \\
\text { follow-up }\end{array}$ & Yes \\
\hline 24 & 3 & Male & $\begin{array}{l}\text { MMR, } \\
\text { hypotonia, } \\
\text { cardiac arrest }\end{array}$ & No & $\begin{array}{l}\text { Suspected nonketotic } \\
\text { hyperglycinemia no } \\
\text { definitive diagnosis }\end{array}$ & $\begin{array}{l}\text { CTTH, similar lesions in } \\
\text { the thalamus and } \\
\text { globus pallidus at } \\
\text { follow-up (hypoxic } \\
\text { encephalopathy) }\end{array}$ & No \\
\hline 25 & 15 & Male & $\begin{array}{l}\text { Altered } \\
\text { consciousness, } \\
\text { desaturation, } \\
\text { hypotension }\end{array}$ & No & $\begin{array}{l}\text { Autoimmune hemolytic } \\
\text { anemia, widespread } \\
\text { cutaneous candidiasis. }\end{array}$ & $\begin{array}{l}\text { CTTH with similar } \\
\text { lesions in the medulla } \\
\text { oblongata bilaterally } \\
\text { (Hypoxic } \\
\text { encephalopathy) }\end{array}$ & Yes \\
\hline 26 & 25 & Male & MMR & No & Mosaic trisomy & None & No \\
\hline 27 & 0 & Male & $\begin{array}{l}\text { Respiratory } \\
\text { arrest }\end{array}$ & No & None & $\begin{array}{l}\text { CTTH with widespread } \\
\text { similar lesions in the } \\
\text { internal capsule and } \\
\text { crus cerebri }\end{array}$ & Yes \\
\hline 28 & 6 & Female & Seizure & No & $\begin{array}{l}\text { Combined } \\
\text { immunodeficiency }\end{array}$ & $\begin{array}{l}\text { CTTH with similar } \\
\text { lesions in the globus } \\
\text { pallidus and crus } \\
\text { cerebri }\end{array}$ & Yes \\
\hline 29 & 29 & Female & $\begin{array}{l}\text { Altered } \\
\text { consciousness }\end{array}$ & No & $\begin{array}{l}\text { Acute lymphoid } \\
\text { leukemia }\end{array}$ & $\begin{array}{l}\text { Periventricular } \\
\text { increased signal. All } \\
\text { findings disappeared } \\
\text { during follow-up }\end{array}$ & No \\
\hline 30 & 0 & Male & $\begin{array}{l}\text { Seizure, } \\
\text { hypotonia }\end{array}$ & No & $\begin{array}{l}\text { Nonketotic } \\
\text { hyperglycinemia }\end{array}$ & $\begin{array}{l}\text { CTTH with similar } \\
\text { findings in the } \\
\text { corticospinal tract and } \\
\text { dentate nuclei, } \\
\text { hypogenesis of the } \\
\text { corpus callosum, } \\
\text { subdural hemorrhage }\end{array}$ & Yes \\
\hline 31 & 215 & Female & Seizure, MMR & Valproate & $\begin{array}{l}\text { Epilepsy, congenital } \\
\text { hearing loss (suspected } \\
\text { congenital } \\
\text { nonsyndromic } \\
\text { sensorineural hearing } \\
\text { loss) }\end{array}$ & $\begin{array}{l}\text { CTTH with similar } \\
\text { lesions in the } \\
\text { cerebellum, brainstem } \\
\text { and widespread in the } \\
\text { cerebral white matter }\end{array}$ & No \\
\hline 32 & 198 & Female & Ataxia & No & Wilson disease & $\begin{array}{l}\text { CTTH with similar } \\
\text { lesions in the thalamus, } \\
\text { lentiform nucleus and } \\
\text { caudate nucleus } \\
\text { bilaterally }\end{array}$ & No \\
\hline 33 & 68 & Female & Seizure & Valproate & Epilepsy & None & No \\
\hline 34 & 0 & Male & Hypotonia & No & Premature & PVL. & No \\
\hline 35 & 24 & Female & Seizure & Levetiracetam & Epilepsy, autism & $\begin{array}{l}\text { CTTH, disappears on } \\
\text { follow-up }\end{array}$ & No \\
\hline 36 & 21 & Male & MMR & No & Atypical autism & None & No \\
\hline 37 & 10 & Female & MMR & No & None & Delayed myelinization & No \\
\hline 38 & 14 & Female & Seizure, MMR & Vigabatrin. & Infantile spasm & $\begin{array}{l}\text { CTTH disappears on } \\
\text { follow-up }\end{array}$ & No \\
\hline 39 & 40 & Male & Ataxia & No & ADEM & $\begin{array}{l}\text { CTTH disappears on } \\
\text { follow-up }\end{array}$ & No \\
\hline
\end{tabular}

Abbreviations: ADEM, acute disseminated encephalomyelitis; CP, cerebral palsy; CRF, chronic renal failure; CTTH, central tegmental tract hyperintensity; GVHD, graft versus host disease; HUS, hemolytic-uremic syndrome; ICU, Intensive Care Unit; LHON, Leber's hereditary optic neuropathy; MELAS, mitochondrial encephalomyopathy, lactic acidosis, Stroke-like episodes; MMR, motor-mental retardation; PVL, periventricular leukomalacia. 